\title{
DOS MODELOS AOS SISTEMAS: UMA ANÁLISE DA JUSTIÇA CONSTITUCIONAL COMPARADA DE LUCIO PEGORARO
}

FROM THE MODELS TO THESYSTEMS: A STUDY OF THE COMPARATIVE CONSTITUTIONAL JUSTICE OF LUCIO PEGORARO

DE LOS MODELOS A LOS SISTEMAS: UN ANÁLISIS DE LA JUSTICIA CONSTITUCIONAL COMPARADA DE LUCIO PEGORARO

\section{Renato Gugliano Herani ${ }^{1}$}

Licença CC BY:

Artigo distribuído sob os termos Creative Commons, permite uso e distribuição irrestrita em qualquer meio desde que o autor credite a fonte original.

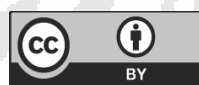

\begin{abstract}
Resumo: O presente artigo oferece uma resenha crítico-informativa do livro Giustizia Costituzionale Comparata: Dai modelli ai sistemi, escrito por Lucio Pegoraro. O livro propõe uma reclassificação dos sistemas de justiça constitucional espalhados pelo mundo, em substituição ao modo dicotômico de classificar esta instituição.
\end{abstract}

Palavras-chave: Constitucional. Comparação. Jurisdição. Modelos. Sistemas.

Abstract: This article offers a critical and informative review of the book Giustizia Costituzionale Comparata: Dai modelli ai sistemi, by Lucio Pegoraro. The book proposes a reclassification of constitutional justice systems around the world, replacing the dichotomic way in which this institution is classified.

Key-words: Constitutional. Comparative. Jurisdiction. Models. Systems.

Resumen: El presente artículo ofrece una reseña crítica informativa del libro Giustizia Costituzionale Comparata: Dai modelli ai sistemi, escrito por Lucio Pegoraro. El libro propone una reclasificación de los sistemas de justicia constitucional distribuidos por el mundo, en substitución al modo dicotómico de clasificar esta institución.

Palabras-clave: Constitucional. Comparación. Jurisdicción. Modelos. Sistemas.

Professor Titular da Faculdade de Direito da FADISP (Brasil), Professor de Direito Constitucional dos Programas de Doutorado e Mestrado em Direito da FADISP (Brasil). Bolsistas da Fundação Nacional de Desenvolvimento do Ensino Superior (Funadesp). E-mail: renato@advgh.com.br. 


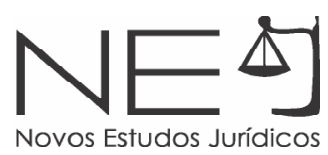

INTRODUÇÃO

O presente estudo é uma resenha crítico-informativa da obra em versão italiana "Giustizia Costituzionale Comparata: Dai modelli ai sistemi"2, de autoria de Lucio Pegoraro3. Por seus méritos e sólidos serviços até aqui prestados ao Direito, em especial ao Direito Constitucional Comparado, Lucio Pegoraro é um autor com um amplo crédito e solvência para além de terrea europeus. É o caso da referida obra que, alicerçada no método comparado meticulosamente refletido e aplicado ${ }^{4}$, muito contribui para o amadurecido das análises científicas sobre a evolução da Justiça Constitucional e seus vários regimes jurídicos.

\section{CONTEXTUALIZAÇÃO DA OBRA}

Especialmente na América Latina, a visão diferenciada de Lucio Pegoraro sobre a circulação, a recepção e a hibridação da jurisdição constitucional ${ }^{5}$ permite a que se suscite uma identidade latino-americana de Justiça Constitucional ${ }^{6}$. Visão particularmente importante para uma região que, a partir dos annus mirabilis ${ }^{7}$ de abundantes reformas constitucionais totais ou parciais entre as décadas de 80 e 90, convive com mudanças que, de tão significativas, têm chamado a atenção para um novo constitucionalismo latino-americano. Alusiva a um período de remodelações constitucionais, essa expressa marca um momento de ruptura com regimes comunistas e totalitários e repercute, dentre outros efeitos, a proeminência da Justiça Constitucional.

Neste contexto latino-americano, a obra resenhada traz uma temática preciosa para o que se tornou um elemento central no estudo do direito processual

2 Lucio Pegoraro. Giustizia Costituzionale Comparata: Dai modelli ai sistemi. Torino: G. Giappichelli, 2015.

3 Lucio Pegoraro é Professor Ordinário de Direito Público Comparado da Università di Bologna e Professor Afiliado da Universidad Autónoma de Nuevo Leon, autor de várias obras.

4 Pegoraro tem uma vasta obra no direito comparado, não só aplicado ao direito constitucional, como também no plano da teoria geral: Derecho constitucional y método comparativo. In: Memoria del Congreso Internacional de Culturas y Sistemas Jurídicos Comparados, Serna de la Garza, UNAM, 2005; Derecho Público Comparado. México: UNAM, 2015; Introducción al derecho público comparado. México: UNAM; Las fuentes en el derecho comparado. Tradução de Marta León; Daniel Berzosa; Jhoana Delgado. Lima: G. Giappichelli, 2003

5 La circulación, la recepción y la hibridación de los modelos de justicia constitucional. Anuario Iberoamericano de Justicia Constitucional: Centro de Estudios Políticos y Constitucionales, Madrid, n. 6, p. 393-416, 2002.

6 Pegoraro reconhece que: "É na América Latina, de fato, que em nenhum outro lugar mais foi posto à prova a teoria sobre a circulação dos modelos" (Giustizia Costituzionale Comparata, Avvertenza.

7 Esta expressão latina é muito utilizada para marcar o período em que em todo o mundo surgem novas Constituições num momento de ruptura com regimes comunistas e totalitários. 
constitucional: a contraposição entre os modelos de Justiça Constitucional. Este tema ganhou importância a partir da Segunda Guerra Mundial, ocasião em que a universalização dos modelos clássicos deu o tom do constitucionalismo. Até hoje subsiste tal expansão, a ponto de constituir-se um dos fenômenos mais relevantes dos ordenamentos de nosso tempo. Atento a este movimento, Pegoraro observa a crença na força paradigmática dos modelos clássicos de Justiça Constitucional (o americano, deflagrado pela lição de Marshall no famoso caso Marbury vs. Madison, e o europeu, delineado pelos ideais kelseniano) para explicar e classificar os modelos praticados nos diversos países. Ícones mundiais, estes modelos acabam por imprimir um modo dicotômico de descrever e comparar a jurisdição constitucional nas várias latitudes mundiais. No entanto, Pegoraro demonstra um ceticismo justificado a este modo de compreender a evolução da Justiça Constitucional. Sustenta que nenhum dos países por seu desenho constitucional responde fielmente àqueles modelos clássicos. Por tal razão, defende a premência da "desconstrução da modelística tradicional"8. Perseguindo tal propósito, a obra é estruturada em três partes. A primeira sedimenta a problemática dos modelos paradigmáticos ("I modelli e la modellistica tradizionali"), para, na segunda parte, propor uma "descontruzione dei modelli" e uma sistemática de "riclassificazioni". Esta norteará, na terceira parte, a análise sobre o discurso político das Cortes e seu papel político ("Il discorso dele corti e il loro ruolo politico").

\section{O MITO DOS MODELOS PARADIGMÁTICOS}

Lucio Pegoraro retoma a ideia generalizada sobre a força classificatória dos modelos clássicos, e a respeito assinala que, se bem foram convertidos em paradigmas para grande número de Estados no século $X X$, hoje essa concepção é muito mais "um mito que não resiste a uma análise corrosiva da observação empírica"9. Justifica a crítica na extraordinária variedade do direito positivo como causa para emancipar-se dos modelos clássicos, e assim "reconstruir"10 em termos doutrinários uma tipologia mais condizente com o que se verifica na prática das diversas democracias mundiais ${ }^{11}$.

8 Giustizia Costituzionale Comparata: Dai modelli ai sistemi, p. 13.

9 Giustizia Costituzionale Comparata: Dai modelli ai sistemi, p. 13.

10 Giustizia Costituzionale Comparata: Dai modelli ai sistemi, p. 13.

11 Essa proposta de reconstrução apoiada no direito comparado permite repensar as bases epistemológicas do processo constitucional. 
Pegoraro não destrona os modelos clássicos, imortalizados no pensamento jurídico. Embora ainda os considere parâmetro para os mais variados ordenamentos jurídicos, a "desconstrução do modelismo tradicional" 12 deve-se ao fato da sua insuficiência para explicar o estado da arte da Justiça Constitucional. Diz que, desde os pós-guerras, inverteu-se a ordem para:

[...] não partir dos Estados Unidos e Áustria, para trazer-Ihes experiências distintas (eventualmente forjando classe mista e híbrida), mas mover-se da extraordinária variedade do direito positivo, e a partir desta (re)construir eventualmente uma classificação ${ }^{13}$.

Por detrás desta ideia, Pegoraro alude que "a motivação de uma ou outra solução prática adotada em matéria de controle de constitucionalidade é mais profunda do que o mero intento de se referir a um modelo"14. E é mesmo, pois o essencial está em identificar a contingência prática de cada Estado, condutora de um modo próprio e possível de aparelhar a jurisdição constitucional em vista da maior efetividade dos direitos e das liberdades fundamentais. Isso, sem dúvida, dificulta o modelismo e abre, diz Pegoraro, para uma sorte de hibridação ${ }^{15}$.

\section{OS ELEMENTOS PERTINENTES DE UMA CLASSIFICAÇÃO MÚLTIPLA E} EXTENSIONAL

O ponto alto da obra está, a nosso ver, na reclassificação dos sistemas de Justiça Constitucional, sob uma proposta elaborada a partir de um conceitochave, aliás, estruturante desta reclassificação, indicado pela expressão elementos pertinentes ("elementi pertinenti") ${ }^{16}$. Esse conceito ganha força opondo-se à ideia de elementos determinantes ("elementi determinanti"). Estes últimos compõem a estrutura genética e por isso fundamental dos "traços de identidade"17 da Justiça Constitucional. Pegoraro associa tais elementos àqueles utilizados por alguns autores, como Mauro Cappelletti ${ }^{18}$, quais sejam:

12 Giustizia Costituzionale Comparata: Dai modelli ai sistemi, p. 13.

13 Giustizia Costituzionale Comparata: Dai modelli ai sistemi, p. 110.

14 Giustizia Costituzionale Comparata: Dai modelli ai sistemi, p. 110.

15 Lucio Pegoraro fala a esse respeito que: "[...] por uma parte alguns ordenamentos uniram elementos dos dois modelos mais antigos, dando lugar a um terceiro tipo, o sistema incidental; por outro, nenhum ordenamento (exceto Estados Unidos e poucos mais) utiliza um só modelo, senão que se enriquece com elementos de outros sistemas" (Giustizia Costituzionale Comparata: Dai modelli ai sistemi, p. 13).

16 Giustizia Costituzionale Comparata: Dai modelli ai sistemi, p. 11.

17 Giustizia Costituzionale Comparata: Dai modelli ai sistemi, p. 11.

18 Mauro Cappelletti. O controle judicial de constitucionalidade das leis no direito comparado. Porto Alegre: Sergio Antonio Fabris Editor, 1999 
titularidade do controle, modalidade de acesso e natureza da decisão. Porque são excludentes, tais elementos promovem uma classificação dicotômica. No entanto, insurgindo-se contra esta visão que só promove uma leitura "tradicional, simplificada e racionalizada da classificação"19, Pegoraro entende que existem outras dimensões a ser exploradas. É aqui que busca na inclusão dos elementos pertinentes "um fator discricionário" 20 que, quando bem utilizado, permite uma classificação sob uma lógica fuzzy ${ }^{21}$, mais pragmática, senão mesmo realista dos sistemas de Justiça Constitucional espraiados pelo mundo. Avança-se, sob esta coordenada, para uma classificação bem diferente da dicotômica, muito mais para múltipla e extensional ${ }^{22}$, porque é estruturada segundo a experiência positiva dos vários desenhos constitucionais e, por isso, convertida numa questão indutiva e de "pertinência"23.

Toda essa discussão sobre os elementos pertinentes reflete um aspecto relevante do pensamento de Pegoraro sobre os critérios de reconhecimento da Justiça Constitucional, que se prende ao fato de que a mesma, a seu ver, reflete sempre determinadas condições sociais. É uma conclusão significativa, pois supera aquela leitura dos desenhos constitucionais da Justiça Constitucional sob a "chave de derivação de arquétipos"24, como se fossem submodelos dos modelos clássicos. A partir deste estofo teórico, Lucio Pegoraro analisa os elementos pertinentes, considerando-os nos diversos direitos positivos. Entre estes elementos, além dos mais tradicionais ${ }^{25}$, estão os ditos pertinentes, os mais importantes, porém em geral ignorados. É a partir deles que se torna possível uma classificação, como dito, múltipla e extensional da Justiça Constitucional, organizada por classes mais fiéis à realidade empírica do sistema observado ${ }^{26}$.

19 Giustizia Costituzionale Comparata: Dai modelli ai sistemi, p.12.

20 Giustizia Costituzionale Comparata: Dai modelli ai sistemi, p. 12.

21 Expressão utilizada num sentido de vagueza ou relativo, na medida em que o elemento só pertence à classe numa certa medida de pertinência (Giustizia Costituzionale Comparata: Dai modelli ai sistemi, p. 202).

22 Giustizia Costituzionale Comparata: Dai modelli ai sistemi, p. 204.

23 Giustizia Costituzionale Comparata: Dai modelli ai sistemi, p. 111.

24 Giustizia Costituzionale Comparata: Dai modelli ai sistemi, p. 111.

25 Indica, como tais, aqueles identificados pelos critérios: da titularidade do controle; o contexto estrutural no qual opera a Corte e o Tribunal Constitucionais; a modalidade de acesso à Corte; as funções desempenhadas; os efeitos das decisões, em relação aos demais Poderes; a qualidade do objeto de controle; e os bens tutelados.

26 Sob esta perspectiva, Pegoraro propõe uma classificação baseada em critérios mais abertos: (a) na natureza política e jurisdicional do controle; (b) na titularidade e estrutura da Justiça Constitucional; (c) na função exercida e no bem tutelado; (d) no parâmetro de controle e objeto de controle; (e) nos legitimados e na modalidade de acesso; (f) e na tipologia e efeitos das decisões (Giustizia Costituzionale Comparata: Dai modelli ai sistemi, Parte II, Capítulo II). 


\section{CONSIDERAÇÕES FINAIS}

A obra de Lucio Pegoraro representa um avanço no estudo da Justiça Constitucional, delineando o que se ousa afirmar uma verdadeira doutrina dos modelos de jurisdição constitucional. Dela pode-se de plano extrair: (a) o polimorfismo da Justiça Constitucional, o que, dentre outras consequências, reforça a importância de seu estudo apoiado no método comparado; (b) o erro de se tentar explicar a Justiça Constitucional pela fisiologia das matrizes clássicas e enquadrá-la numa geração de protótipos (americanos ou europeu-kelsenianos); (c) e a certeza de que, na verdade, existem não modelos repetidos ou derivados, mas novas soluções que, embora de inspirações remissivas aos modelos clássicos, oferecem, ao fim, sistemas de grande originalidade.

\section{REFERÊNCIAS DAS FONTES CITADAS}

CAPPELLETTI, Mauro. O controle judicial de constitucionalidade das leis no direito comparado. Porto Alegre: Sergio Antonio Fabris Editor, 1999.

PEGORARO, Lucio. Giustizia costituzionale comparata: dai modeli ai sistemi. Torino: G. Giappichelli, 2015.

. La circulación, la recepción y la hibridación de los modelos de justicia constitucional. Anuario Iberoamericano de Justicia Constitucional: Centro de Estudios Políticos y Constitucionales, Madrid, n. 6, p. 393-416, 2002.

, Derecho constitucional y método comparativo. In: Memoria del Congreso Internacional de Culturas y Sistemas Jurídicos Comparados, Serna de la Garza, UNAM, 2005.

; RINELLA, Angelo. Derecho Público Comparado. México: UNAM, 2015.

; RINELLA, Angelo. Introducción al derecho público comparado. México: UNAM, p. 69.

; RINELLA, Angelo. Las fuentes en el derecho comparado. Tradução: Marta León; Daniel Berzosa; Jhoana Delgado. Lima: G. Giappichelli, 2003.

Recebido em: 19/02/2018

Aprovado em: 22/04/2019 